\title{
Transfuguismo, su matriz histórica. Entre la libertad y la anomia en la institucionalidad política
}

\author{
César Delgado-Guembes
}

En el presente artículo se pretende plantear el contexto en el que aparece y se desarrolla el transfuguismo, así como la estructura y tipicidad del fenómeno desde el punto de vista jurídico. El contexto se define a partir de la matriz histórica presente, la misma que tiene una configuración visible e identificable desde la última década del siglo pasado. Y en la tipicidad jurídica del transfuguismo importa el reconocimiento de los presupuestos y elementos de dicha figura, en la que no cabe presumir carácter ilícito ni delictivo.

A partir del análisis y reflexiones de las condiciones culturales presentes y de la estructura jurídica de esta figura en el comportamiento de los actores políticos, se concluye que el deseo del tránsfuga es un deseo estructurado por la interacción que avala el espíritu de los grupos políticos en los que se da una filiación tránsfuga. Como remedio para contener el desborde y la anomia inherentes al transfuguismo, se presenta la posición consciente de ciudadanos y líderes frente a la cultura utilitaria e individualista hegemónica, que carece de valoraciones respecto del carácter orgánico de la república y la función que cumple la persona que desarrolla su vida política en ella. El deseo de hacer vida política en el Parlamento debe entenderse no solo como la pulsión libidinal que avasalla con todo lo que pueda impedir o detener el acceso al mayor goce y acceso al poder, sino como un impulso para combinar el acceso y goce del poder en un marco condicionado por el servicio y no aprovechamiento de los ciudadanos a quienes se representa.

Profesor de Derecho Parlamentario en la Facultad de Derecho de la Pontificia Universidad Católica del Perú, y de la misma materia y del Seminario de Tesis en la maestría en Derecho Constitucional de la misma casa de estudios. 


\section{Matriz histórica del transfuguismo político}

Cuando Garretón señala que los países latinoamericanos no son explicables a partir de una tipología común para los problemas que afectan su desarrollo, económico o político, plantea la necesidad de conocer en profundidad la casuística a partir de una comprensión empírica e histórica más detallada y profunda de la realidad de cada república. ${ }^{1}$ Si bien Garretón, Manin, ${ }^{2}$ Abal Medina ${ }^{3}$ y

Garretón, Manuel Antonio, Cavarozzi, Marcelo, Cleaves, Peter y otros. Latinamerica in the twenty-first century: toward a new sociopolitical matrix. Miami: North-South Center Press, University of Miami, 2003, p. iii. No obstante la diversidad empírica de alternativas propias de cada país, Garretón define los elementos que caracterizan un sistema o matriz para toda la región, la misma que comprende y está compuesta de cuatro procesos: (1) la construcción de democracias políticas; (2) la democratización social, incluida la integración nacional; (3) la reinserción de las economías latinoamericanas en el sistema mundial; y (4) la construcción de un modelo de modernidad que asuma tanto la globalización como las identidades culturales (Garretón y otros, ob. cit., p. 93).

2 Manin, Bernard. Los principios del gobierno representativo. Alianza Editorial, 1998, pp. $267-$ 286. Manin observa que más allá de la continuidad o cambios de las condiciones económicas o culturales, el elector de la etapa a la que Ilama «democracia de audiencia» define su voto no por el partido ni el programa que este tiene sino por la persona del candidato al que otorga su voto (en lo que diverge de la etapa que concluye hacia fines de la década de 1980, conocida como «democracia de partidos» o partidocracia). Señala Manin que este tipo de comportamiento electoral se debería, en primer término, al mayor protagonismo que tienen en la cobertura de las incidencias políticas los medios de comunicación, usados también de modo intenso por los representantes para llegar al electorado (p. 268). Y en segundo lugar, a que como resultado de la mayor complejidad de las políticas que debe atender el Estado, se genera una diversidad de problemas respecto de los cuales no es fácil proponer programas o plataformas antes de una elección, por lo cual los cargos de representación quedan afectados en su esencia por un amplio marco de imprevisión. En consecuencia, con este tipo de comportamiento del electorado, afirma Manin, puede estar comenzando la era de votar el historial de los gobernantes (p. 271), era que tiene expresiones como la hoja de vida o, con mayor precisión, el historial de las votaciones expresadas durante el mandato parlamentario mediante el tablero electrónico del Congreso.

3 Abal Medina, Juan. La muerte y la resurrección de la representación política. Fondo de Cultura Económica, 2004, pp. 55-95. Abal Medina habla del surgimiento de un modelo de representación postsocial, democracias demoscópicas y metaelectorado que inciden en la configuración de un sistema político que privilegia un mercado de opinión pública, con participación activa de los medios de comunicación, a partir del cual los partidos definen sus tácticas en una lógica mediática, donde el motor gira alrededor de una ansiedad por el humor popular que se deriva de las encuestas de opinión (poll anxiety). Por otro lado, en su artículo «Elementos teóricos para el análisis contemporáneo de los partidos políticos: un reordenamiento del campo semántico», Abal Medina recuerda la aclaración de Sartori en el sentido de que los partidos no son solo objeto, sino que, dentro de una perspectiva institucional, son sujetos de los procesos políticos que constriñen la voluntad del electorado, y ello ocurre en contextos en los que a pesar de tratarse de las mismas identidades partidarias, los partidos hayan cambiado sus estrategias de captación de votos en un modelo o estructura cambiante de competencia (en El asedio de la política. Los partidos latinoamericanos en la era neoliberal, compilación de Cavarozzi y Abal Medina publicada en el 2002, pp. 53-54). 
Grompone $e^{4}$ coinciden en fijar el inicio de un período sociopolítico diverso al concluido hacia inicios de la década de 1990, el inicio de este nuevo contexto requiere la redefinición teórica a partir de las distintas maneras en que interactúan los elementos básicos de la matriz sociopolítica. Uno de los elementos propios de esta matriz es el sistema de representación política.

La representación política se expresa, a pesar de los cambios históricos recientes, y no obstante la presencia de nuevos actores y de sus distintos modos de organización interna o de apelación a la voluntad popular en los diversos escenarios electorales, en los partidos políticos. Estos se organizan e interactúan con la sociedad y con el Estado de diverso modo a partir, aproximadamente, de comienzos de la década de $1990,{ }^{5}$ coincidiendo con una crisis generalizada

4 Grompone, Romeo. «El incierto futuro de los partidos políticos». En Perú 1964-1994. Economía, sociedad y política. Lima: IEP, 1995, pp. 181-199. En el acápite sobre la reconstrucción de los partidos luego de la crisis de mediación observada tanto en América Latina como en Europa, señala Grompone que «[...] estamos ante el fin de una cultura política, los partidos ya no van a ser los que conocimos alguna vez y en muchos países corren definitivamente el riesgo de perder vigencia [...]. En estos nuevos movimientos de independientes la oposición pierde sentido ya que no hay propuestas fundacionales que sirvan de referencia ni la apelación a un auge organizativo que se haya vivido alguna vez y al cual invocar en las circunstancias presentes para rebelarse contra lo establecido» (pp. 198-199). Esa nueva cultura política, sostenida en gran medida por las clases medias, es a la que Kathya Araujo ubica en lo que, siguiendo a Beatriz Sarlo, Ilama la lógica del mercado, y en el acto de consumo, lo que se expresa en una identidad a través de los objetos (ver su «Sujeto y cultura desde el psicoanálisis», en Las clases medias: entre la pretensión y la incertidumbre, Taller de Estudio de las Mentalidades Populares (TEMPO), 1998, p. 472).

5 Así como, a nivel global, el sistema de interacción partidaria adopta un perfil con identidad singular desde fines de la década de 1990, su aparición tiene en el Perú una sucesión puntual de causas perfectamente discernibles. Más allá de los fenómenos propios del desarrollo mundial de orientaciones culturales, económicas y políticas, la década del ochenta creó en el Perú el terreno propicio para los fenómenos constatados desde los años noventa, ciertamente, como es la adaptación a nuevas formas de organización por los actores antiguos de los procesos políticos o la aparición de nuevos actores en la política nacional. En la década de 1980, en efecto, se da lo que Julio Cotler llamó el desencanto con la política («Crisis políticas, «outsiders» y democraduras: el fujimorismo», en Partidos y clase política en América Latina en los 90, 1995), que resultó de la ineficacia en los esfuerzos de mediación de las estructuras partidarias insuficientemente consolidadas en un proyecto que no cuajó y que, por el contrario, se diluyó con estrategias de clientelismo. Esto último lleva a algunos autores a dudar de que en el Perú haya habido en efecto un sistema de partidos (por ejemplo, Julio Cotler, Nicolás Lynch o Agustín Haya de la Torre) ni oportunidad efectiva para que se dé el espacio necesario para que exista una auténtica competencia democrática o de que estos hayan alcanzado niveles de organización o tendencias centrales fuera de las coyunturas electorales, circunstancias que Ilevan a Lynch a sostener que antes que sistema, en el Perú se ha dado más bien un "protosistema o intento de construir un sistema de partidos» (Nicolás LYNCH, Una tragedia sin héroes. La derrota de los partidos y el origen de los independientes en el Perú, 1980-1992, 1999, pp. 49-53). Como consecuencia del proyecto infructuoso o trunco de generación de un sistema de partidos, es que aparece la alternativa de mediación entre sociedad y Estado que se configura con el protagonismo de gremios, organizaciones populares y barriales, asociaciones de micro y pequeños productores, no menos que de los propios medios de comunicación, los mismos que reciben auspicio de otros núcleos fácticos e importantes de poder político como son las iglesias, las ONG 
a nivel mundial ${ }^{6}$ que concluye un período cuyo proceso político ha sido conocido por analistas, políticos y opinión pública como la etapa del Estado y de la democracia partidocéntrica o partidocrática. ${ }^{7}$ Similarmente, la interrelación de los partidos entre sí conforma un sistema de partidos, el que luego de la modalidad de interrelación concluida antes de la década del noventa cambia ${ }^{8}$ y adquiere un perfil diferente - donde si bien subsisten elementos del sistema anterior, aún no termina de definirse, y menos de consolidarse, una identidad general universalmente oponible en diversas latitudes y países-.

Si el objetivo es indagar empíricamente respecto del tipo de sistema de partidos y el funcionamiento de los partidos políticos, y estos a su vez deben ser evaluados según el tipo de sistema, el momento histórico y las condiciones culturalmente hegemónicas en las que la interacción entre los partidos se da, resulta necesario estudiarlos en el contexto del sistema de relaciones sociales e institucionales que se expresan en los subsistemas de Estado, de sociedad, de economía, de régimen político, de partidos propiamente dicho y, por último,

y los organismos internacionales, que apoyan la mediación según criterios demoscópicos orientados por las encuestas de opinión (ver Agustín HAYA DE LA TORRE, Dictadura y democracia. La crisis del Estado republicano, Foro Democrático, 2003, pp. 234-241).

6 Dice Przeworski que «[...] los partidos políticos experimentan hoy una declinación continua en casi todo el mundo y en la mayor parte de las nuevas democracias están muy fragmentados, son débiles desde el punto de vista organizativo y son poco representativos». Ver Adam Przeworski, Torcuato di Tella, José María Maravall, Guillermo O’Donnell, Philippe Schmitter, Alfred Stepan y otros, Democracia sustentable, Paidós, 1995, p. 86.

7 Cabe enunciar que fue Alberto Fujimori quien, en una lógica antisistema, expresó la declaración de defunción de los «partidos tradicionales», a los que responsabilizó como agencia oligárquica del divorcio entre la sociedad civil y la ciudadanía, y el Estado, generadora de centralización del poder, del patrimonialismo clientelista y rentista en la esfera pública y de la fragmentación social, en beneficio de las dirigencias y de la burocracia partidaria. La acogida del diagnóstico fue general y la aprobación de las definiciones que hizo significaron la sepultura de un sistema de interacciones interpartidarias y partido-Estado que empieza a reemplazarse a partir precisamente del autogolpe de 1992.

8 Si para Sartori cabe hablar de cambio del sistema de partidos, a partir de la perspectiva parsoniana en la que sustenta su concepto de sistema, cuando se producen cambios en el sistema de interacción que resulta de la competencia intrapartidaria (Giovanni SARTORI, Partidos y sistemas de partidos, Alianza Editorial, 1994, pp. 66-67), Peter Mair puntualiza que el cambio en el sistema de partidos ocurre cuando un sistema de partidos se transforma de un tipo o clase de sistema de partidos en otro. La clasificación de los sistemas de partidos a su turno varía según el criterio central de interacción (por lo tanto, se excluyen criterios marginales de interacción), que puede incluir el número significativo de partidos en competencia, el nivel en que se ubica el tipo de interacción en el continuo de fragmentación, concentración o atomización (según la tendencia monocrática o hegemónica, o el pluralismo y dispersión), la distancia o centralidad ideológica (a mayor centralidad, mayor incentivo para impulsos centrífugos o de polarización), la presencia o desaparición de partidos ideológicamente situados en una posición antisistema, la ideologización o pragmatismo, o el pase de un sistema de partidos tipo partidos de masas a un sistema de partidos orientados al mercado bajo el formato de los catch-all parties. Ver: Peter MAIR, Party system change. Approaches and interpretations, Clarendon Press, 1997, pp. 51-54, y Giovanni SARTORI, Partidos y sistemas..., pp. 149-287. 
electoral, que es a lo que Garretón llama la matriz histórica e institucional del sistema político.

Es dentro de la actual matriz histórica que corre a partir de la última década del siglo XX que se muestra una preferencia por un esquema de democracia pluralista, radical, sin mayor estructuración, abierta a la contingencia y contraria o crítica frente a la hegemonía mediadora de los partidos. Dicho esquema se define como uno de democracia sin partidos. Su postulación pretende un cambio en el sistema representativo a partir de movimientos sociales más o menos volátiles, mediante los cuales se incida en la mayor proximidad y cercanía entre los representantes y los electores y en un nivel real de significación del mandato que ofrezca mejor garantía del vínculo fiduciario entre la colectividad y sus representantes.

Este tipo de visión de la democracia y del sistema representativo no tiene un mensaje especial, sin embargo, respecto de la funcionalidad y exigencias institucionales desde las que deben operar los representantes. Para quienes subrayan la representación, las ineficiencias del Congreso se refieren a la pobreza o precariedad del vínculo político con la diversidad de localidades por las que se postulan y las que los eligen. Para quienes, de otro lado, enfatizan el desempeño de las instituciones estatales a las que llega la representación, las ineficiencias están referidas al carácter estatal de las funciones sociales que tiene en una sociedad respecto de la supervivencia de la colectividad como un todo.

Entre representatividad y eficiencia, el punto central es el desempeño de los partidos parlamentarios durante los períodos por los que se les otorga el mandato de representación. No hay otro modo de conocer el perfil del sistema de partidos parlamentarios que a través de la constatación de su operación y funcionamiento. Si toda comunidad política cuenta con agentes de intermediación para asegurar la representación de la sociedad ante el Estado, es el modo en el que dichos agentes interactúan lo que define el sistema de partidos. Los factores que definen el sistema son aspectos como la cultura de representación, la organización interna de las agrupaciones, la estructura competitiva y el tipo de estilo utilizado entre dichos agentes para interactuar, para comunicarse y para resolver las materias pendientes de decisión colectiva.

\section{2. ¿Síntoma de anomia o anomia sistémica?}

Si bien algunos perciben y tratan el transfuguismo como una causa de la fluidez y de las tendencias a la falta de cohesión del sistema de partidos, otros lo ven más como un efecto tanto de las normas electorales como de la cultura política de los actores. En cualquier caso, el transfuguismo es un fenómeno que aparece como un sintoma del sistema de representación política en general, y de los sistemas de partidos políticos en particular, cuya génesis y desarrollo es interesante a 
la vez que necesario abordar, de modo que se aclare su naturaleza y se explique su significación como expresión del sistema político.

\subsection{Contexto sistémico y causas del transfuguismo}

Según se ha sostenido en este trabajo, el transfuguismo ocurre en la actual época histórica con mayor frecuencia que en la inmediata anterior a los años noventa. Su difusión coincide con fenómenos como la desideologización del sistema político, vinculada a su vez al debilitamiento general del sistema de partidos de masas — que supuso la inclusión de sectores económica y socialmente marginados hasta la segunda y tercera décadas del siglo XX-, la conclusión del sistema internacional bipolar, el predominio de la economía de mercado y el capitalismo global como ideología económica indiscutidamente hegemónica, la democratización de la información y de las tecnologías de la información, así como el papel destacado de los medios de comunicación y de las técnicas demoscópicas en la escena política.

En este marco general emergen dos notas características a partir de inicios de la década de 1990. Una primera es un tipo de partido político altamente volátil en su organización y plana de adscritos, al que Panebianco llamaría partidos electorales profesionales ${ }^{9}$ y al que otro sector de la bibliografía conoce familiarmente como catch-all parties, 'partidos atrapalotodo', ${ }^{10}$ en un esquema general que configura el sentido de orientación e imprime dirección al sistema de partidos y no solo a uno o varios de los partidos que lo constituyen, a tal grado que alcanza nivel normativo en los líderes, las organizaciones y sus estrategias,

9 Panebianco, Angelo. Political parties: organization and power, Cambridge, 1988. Según este autor, se trata de los partidos en los que la organización del partido incluye a dirigentes que tienen la condición de profesionales y consultores antes que de militantes burocratizados.

10 Si bien el concepto es acuñado en «The transformation of West European party systems» por Otto Kircheimer allá por el año 1966, en la obra que dicho año compilaron LaPalombara y Weiner, Political parties and political development, la denominación constituye hoy un lugar común entre los comentaristas de los sistemas de partidos. Por ejemplo, Peter Mair y Richard Katz, en el artículo «Party organization, party democracy, and the emergente of the cartel party» (1997), incluido en la obra citada, Party system change. Approaches and interpretations, de Peter Mair, precisa que los partidos atrapalotodo son aquellos en los que no hay emergencia desde la sociedad civil, como ocurre en los partidos de masas, sino que aparecen como intermediarios entre la sociedad civil y el Estado, con el propósito de influenciar en el Estado desde afuera, pretendiendo la custodia de las políticas públicas «[...] con la finalidad de satisfacer las demandas a corto plazo de un estilo pragmático de consumidores» (ob. cit., p. 97). Es a este estilo y visión pragmática de audiencia electoral al que apelan los partidos que aspiran a posicionarse como opciones atractivas y exitosas en el proceso de alcanzar escaños en el Congreso y en el gobierno, audiencia electoral que, por lo general, tiene una concepción desfavorable frente a estructuras partidarias jerarquizadas y burocratizadas al estilo que prevaleció hasta fines de los años ochenta en la época de los partidos de masas, pero a la vez favorables a los outsiders y a las narrativas antisistémicas y contrarias a la profesionalización de la política. 
los mismos que se conceptúan y actúan como brokers de la sociedad civil ante el Estado. ${ }^{11}$ Una segunda nota es el ascenso de los outsiders en la escena política - calificables, igualmente, como free riders en los colectivos gracias a los cuales llegan a la representación-, como alternativa crítica frente a la lógica organizacional de mayor rigidez relativa del sistema de partidos de masas. ${ }^{12}$ Los outsiders de la matriz pluralista incipiente que se inicia en los años noventa, sin embargo, resultan de una concepción antisistémica ${ }^{13} \mathrm{y}$, por lo tanto, aparecen como un signo de contradicción que niega el carácter pluralista de la democracia en cuyo nombre critican el tipo de democracia y de representación que protagonizan, en la matriz precedente, los partidos llamados tradicionales. ${ }^{14}$

11 MAIR Y KATZ, ob. cit., p. 104. Ambos autores afirman que el partido concebido como broker o intermediario entre la sociedad civil y el Estado es compatible con el concepto de democracia pluralista, entendida como espacio de negociación y compromiso de intereses independientes y organizados, en el que los partidos construyen constantemente coaliciones entre dichos intereses actuando como facilitadores del compromiso y como garantía contra la explotación de un grupo en contra de otros, de modo que cada partido asuma una actitud abierta respecto de todo tipo de intereses.

12 En el capítulo sobre el cambio de matriz que aparece en el texto colectivo que lidera Garretón, advierte que en los países que no existen partidos en sentido estricto (vale decir, partidos volátiles, constituidos y construidos primariamente como partidos atrapalotodo), se presentan problemas cruciales de representación y de formulación de proyectos políticos, como ocurre en la constatación de que la colectividad resulta siendo representada de modo espurio por personalidades con ambiciones políticas que provienen de los medios de comunicación, la industria del entretenimiento, los deportes, la carrera militar, de fueros del antipartido o de lobbies particulares o privados con niveles visibles de influencia social, que ilustra Garretón con los ejemplos peruano, ecuatoriano y venezolano. En GARRETÓN, CAVArOzZI, Cleaves, GerefFi, y Hartlyn, Latin America in the Twenty-First Century: toward a new sociopolitical matrix, North-South Center Press, 2003, pp. 78-79.

13 La aparición generalizada de outsiders o independientes ha sido causa de asombro en el escenario nacional. Alberto Adrianzén recordaba no solo los casos de Belmont y de Fujimori en 1989 y 1990, sino, además, los datos de las elecciones municipales del año 1993, cuando se presentaron, en promedio, 19 listas de candidatos por cada distrito en la provincia de Lima, para un total de 797 listas en los 43 distritos. Ver su «Gobernabilidad, democracia y espacios locales», en Sociedad, partidos y Estado en el Perú. Estudios sobre la crisis y el cambio, publicación coordinada por Carlos Fernandez Fontenoy (1995). Sin embargo, es necesario apuntar que el carácter antisistémico de quienes protagonizan esta modalidad y estilo de intermediación difiere significativamente de los discursos y propuestas antisistema como los que recuerda Fernández Fontenoy se dieron desde fines del siglo XIX e inicios del XX, con la crítica de Gonzalez Prada, los movimientos anarquista, indigenista, socialista y aprista (hasta 1940), o el Ejército de Liberación Nacional o el MIR (hasta 1968), Velasco Alvarado, el Partido Comunista del Perú (Sendero Luminoso) y el Movimiento Revolucionario Túpac Amaru (MRTA). Ver su «Partidos antisistema y polarización política en el Perú (1930-1994)», en ob. cit., pp. 191-207.

14 La experiencia peruana es paradigmática de la contradicción. Fujimori apela a un tipo de democracia más eficiente, plural, participativa y representativa, pero para alcanzarla, en su condición de outsider del sistema representativo tradicional, apunta a la eliminación de los partidos tradicionales, lo cual supone igualmente el vaciamiento de contenidos democráticos bajo el camuflaje de un tipo plebiscitario de legitimidad cuya naturaleza y corte fueron innegablemente autoritarios. 
El cuadro 1 presenta la relación entre los sistemas y las características del contexto en el que aparece el transfuguismo como efecto de dicho contexto. ${ }^{15}$

\section{Cuadro 1.}

Causas y manifestaciones del transfuguismo

\begin{tabular}{|c|c|c|}
\hline Causas sistémicas & Vínculo operativo & Manifestaciones del proceso \\
\hline Reducción del Estado & $\begin{array}{l}\text { - El sistema de estados soberanos indepen- } \\
\text { dientes e inseguros en proceso a transfor- } \\
\text { marse en un sistema regulado supraestatal- } \\
\text { mente mediante una ideología global } \\
\text { hegemónicamente definida. } \\
\text { - Limitación de lazos de clientelismo (el } \\
\text { cacicazgo del populismo se transforma en } \\
\text { clientelas segmentadas menos territoriales). } \\
\text { - Minimización del rol promotor e } \\
\text { intervencionista del Estado en el sistema } \\
\text { productivo e industrial, así como en el de- } \\
\text { sarrollo de un sistema de justicia social ba- } \\
\text { sado en la igualdad de oportunidades. }\end{array}$ & $\begin{array}{l}\text { - Miembros de partidos carecen de medios } \\
\text { para satisfacer necesidades de sus electores. } \\
\text { - Miembros de partidos se desalientan por } \\
\text { dificultad para atender a su clientela. } \\
\text { - Desembalse acumulado de clientela de- } \\
\text { bilita calidad del vínculo de los represen- } \\
\text { tantes. } \\
\text { - Exclusión de demandas sociales tradicio- } \\
\text { nales e insuficiente atención de sectores } \\
\text { nuevos de demanda política por límites } \\
\text { institucionales y normativos. }\end{array}$ \\
\hline $\begin{array}{l}\text { Unipolaridad de ideología } \\
\text { económica }\end{array}$ & $\begin{array}{l}\text { - Sociedad y economía de mercado trasladan } \\
\text { e impulsan su lógica en la esfera pública. } \\
\text { - La competitividad es la regla en las relacio- } \\
\text { nes económicas y, por transposición, tam- } \\
\text { bién en las relaciones políticas. } \\
\text { - Sociedad políticamente más competitiva } \\
\text { entre facciones y fracciones de intereses so- } \\
\text { ciales y políticos. } \\
\text { - Debilitamiento de la representación formal } \\
\text { en beneficio de una lógica de representa- } \\
\text { ción material y práctica de intereses econó- } \\
\text { micos, culturales, etc. }\end{array}$ & $\begin{array}{l}\text { - El elector se convierte en un consumidor } \\
\text { de bienes electorales y reclama por su in- } \\
\text { satisfacción a través de su respuesta en } \\
\text { encuestas o entrevistas. } \\
\text { - La unipolaridad ideológica configura el } \\
\text { continuo de opciones electorales en un } \\
\text { marco pragmático e instrumental de uni- } \\
\text { dades partidarias. }\end{array}$ \\
\hline
\end{tabular}

15 La relación entre los factores que se registra en las columnas es tomada de lecturas hechas de textos como los de Jean Baudrillard (Cultura y simulacro y La ilusión del fin); Ulrich Beck (¿Qué es la globalización? Falacias del globalismo, respuestas de la globalización); Manuel Castells (La era de la información); Cornelius Castoriadis (El avance de la insignificancia); Guy Debord (La sociedad del espectáculo); Régis Debray (El Estado seductor. Las revoluciones mediológicas del poder); Michael Hardt y Antonio Negri (Imperio, y Multitud); David Held (La democracia y el orden global, y Global transformations); Samuel Huntington (EI orden político en las sociedades en cambio); Gilles Lipovetsky (La era del vacío); Nicolás Lynch (Una tragedia sin héroes. La derrota de los partidos y el origen de los independientes en el Perú, 1980-1992); Jean-François Lyotard (La condición postmoderna); Bernard Manin (Los principios del gobierno representativo); Douglas W. Rae (Political consequences of electoral rules); y Giovanni Sartori (Partidos y sistemas de partidos, y Homo videns. La sociedad teledirigida). 


\begin{tabular}{|c|c|c|}
\hline Causas sistémicas & Vínculo operativo & Manifestaciones del proceso \\
\hline $\begin{array}{l}\text { Transformación de la } \\
\text { sociedad industrial en } \\
\text { sociedad de la informacion }\end{array}$ & $\begin{array}{l}\text { - Ascenso de la empresa mediática como fac- } \\
\text { tor de ideologización y cohesión de la opi- } \\
\text { nión pública. } \\
\text { - Sobredimensión del impacto político de las } \\
\text { encuestas de opinión. } \\
\text { - Intermediación a través del marketing en la in- } \\
\text { vención o construcción de la imagen pública. } \\
\text { - El individuo tiene acceso a cantidades masi- } \\
\text { vas de información. } \\
\text { - El desarrollo crítico de la industria mediática } \\
\text { debilita la autoridad representativa del sis- } \\
\text { tema partidocéntrico precedente. }\end{array}$ & $\begin{array}{l}\text { - La política se conceptúa según reglas del } \\
\text { espectáculo, la pantalla y la publicidad. } \\
\text { - Las nuevas tecnologías de la información } \\
\text { aceleran el descontento. } \\
\text { - La mayor información es insuficiente- } \\
\text { mente comprendida y asimilada por } \\
\text { quienes acceden a ella. } \\
\text { - La menor marginalización de sectores } \\
\text { previamente no incluidos no llega a ser } \\
\text { asimilada satisfactoriamente en los pro- } \\
\text { cesos políticos. }\end{array}$ \\
\hline $\begin{array}{l}\text { El sistema politico } \\
\text { informal hegemoniza los } \\
\text { procesos representativos }\end{array}$ & $\begin{array}{l}\text { - Despolitización de la vida social (decaden- } \\
\text { cia de la política). } \\
\text { - Poderes constituidos disminuyen carecen de } \\
\text { centralidad representativa para articular de- } \\
\text { mandas sociales. } \\
\text { - La pluralidad de diferentes narrativas y dis- } \\
\text { cursos neutraliza la pretensión de narrativas } \\
\text { de ideologización universal en los partidos. }\end{array}$ & $\begin{array}{l}\text { - El control y la supervigilancia son asumi- } \\
\text { dos por voceros no elegidos de la sociedad } \\
\text { civil (ONG y medios de comunicación). } \\
\text { - El esquema participativo sin una infraes- } \\
\text { tructura que canalice la atención eficaz de } \\
\text { la demanda facilita la saturación del siste- } \\
\text { ma de representación y activa la intensi- } \\
\text { dad de la insatisfacción del electorado. } \\
\text { - Partidos se mantienen en una lógica de } \\
\text { interacción que minimiza el enlace con } \\
\text { la sociedad civil. }\end{array}$ \\
\hline $\begin{array}{l}\text { Partidos organizados seguin } \\
\text { reglas de marketing (un } \\
\text { tipo distinto de sistema de } \\
\text { partido) }\end{array}$ & $\begin{array}{l}\text { Desideologización es compensada con téc- } \\
\text { nicas de identificación según tomas de opi- } \\
\text { nión por encuesta. } \\
\text { - Aparición visible y en casos dominante de } \\
\text { actores nuevos en los procesos políticos } \\
\text { (outsiders). } \\
\text { - Los partidos adoptan la estrategia del mer- } \\
\text { cado y se organizan como empresa política } \\
\text { en relación con clientes (votantes). }\end{array}$ & $\begin{array}{l}\text { - Partidos observan una estrategia más } \\
\text { pragmática que de principios. } \\
\text { - Partidos no necesitan guardar consisten- } \\
\text { cia con su ideario y programas. } \\
\text { - Debilitamiento del vínculo de los parti- } \\
\text { dos con sus miembros. } \\
\text { - Partidos se mimetizan en la opinión me- } \\
\text { dida y minimizan el rol y participación } \\
\text { de los militantes tradicionales. }\end{array}$ \\
\hline $\begin{array}{l}\text { Personalización del } \\
\text { sistema electoral }\end{array}$ & $\begin{array}{l}\text { - El paso del distrito nacional a distrito múl- } \\
\text { tiple estrecha la relación entre el elector y su } \\
\text { representante. }\end{array}$ & $\begin{array}{l}\text { - La mayor cantidad de distritos peque- } \\
\text { ños y el uso de listas no bloqueadas per- } \\
\text { sonalizan el lazo de representación en per- } \\
\text { juicio del vínculo con el partido. } \\
\text { - Dinámica electoral centrífuga de opcio- } \\
\text { nes sin capacidad ni eficacia de los parti- } \\
\text { dos para centralizarlas ni fomentar la leal- } \\
\text { tad con el sistema. }\end{array}$ \\
\hline
\end{tabular}




\subsection{Efectos causados por el transfuguismo}

Cuando se examina el transfuguismo como causa de efectos en el sistema, cabe advertir que la constatación de su ocurrencia es una condición que induce con facilidad a asumir que reducida o eliminada su ocurrencia, deja de afectar el sistema político. Si el transfuguismo fuera efectivamente la causa de los males que se presume que ocasiona, obviamente que su desaparición pudiera también hacer desaparecer los males cuya existencia se imputan a su presencia. Sin embargo, el transfuguismo no es propiamente una causa sino un resultado de una época, de reglas, de una cultura y de hábitos del sistema de representación.

El hecho del transfuguismo es en realidad un síntoma que, aparentemente, atraviesa una diversidad de experiencias. El transfuguismo expresa una diversidad de motivos o deseos y manifiesta tendencias que han llegado a ser canalizadas con este tipo de conductas que tienden a propagarse en distintas latitudes. Probablemente haya deseos, tendencias y conductas comunes en todos los sistemas en los que el transfuguismo se presenta y encontrar las causas comunes debe tomar tiempo. Hasta que no se cuente con la suficiente información y casuística, todo intento no debiera pasar de una serie de especulaciones e interpretaciones sobre este fenómeno. Para que las especulaciones e interpretaciones tengan mayor asidero y confiabilidad, por ello, es necesario estudiar cada caso nacional en particular, y en el plano nacional, tener presente la particularidad y detalle de cada caso singular. No obstante, cabe proponer un esquema de efectos generados en el sistema de representación y en el sistema de partidos, a partir de características estructurales del fenómeno del transfuguismo. El cuadro 2 pretende plantear las características a partir de las cuales se manifiestan los rasgos o efectos visibles que configuran el transfuguismo. ${ }^{16}$

16 El esquema contiene características y efectos cuya expresión ha sido sintetizada como resultado de mi trabajo anterior "Transfuguismo y crisis postelectoral en el proceso de reinstitucionalización democrática» (Revista Derecho de la Facultad de Derecho de la Pontificia Universidad Católica, número 53, diciembre 2000, pp. 89-132) y de las lecturas realizadas de Romeo Grompone (Elecciones 1990. Demonios y redentores en el nuevo Perú. Una tragedia en dos vueltas; El velero en el viento. Política y sociedad en Lima; y Las nuevas reglas de juego. Transformaciones sociales, culturales y políticas en Lima); César Landa Arroyo (Transfuguismo); Sinesio Lopez (Ciudadanos reales e imaginarios. Concepciones, desarrollo y mapas de la ciudadanía en el Perú); Simona Piattoni (Clientelism, interests, and democratic representation. The european experience in historical and comparative perspective); Josep María Reniu Vilamala («La representación política en crisis: el transfuguismo como estrategia política», en El Debate sobre la crisis de la representación política, editado por Antonio J. Porras Nadales); y Martín Tanaka (Los espejismos de la democracia. El colapso del sistema de partidos en el Perú; y Democracia sin partidos). 
Cuadro 2.

Manifestaciones causadas por el transfuguismo

\begin{tabular}{|c|c|}
\hline $\begin{array}{l}\text { Características del } \\
\text { transfuguismo }\end{array}$ & Rasgos del sistema político con que se manifiestan las características \\
\hline $\begin{array}{l}\text { Alteración de la estructura } \\
\text { de bloques representativos } \\
\text { de la sociedad articulados } \\
\text { con titularidad politica en } \\
\text { el Estado }\end{array}$ & $\begin{array}{l}\text { - Desacoplamiento de la identidad ideológica entre sistema de partidos y sociedad. } \\
\text { - Sustitución no institucional ni legal del proceso de selección de opciones de representa- } \\
\text { ción política. } \\
\text { - Volatilización de la propuesta y responsabilidad de los partidos en el proceso de rendi- } \\
\text { ción de cuentas ante la sociedad. } \\
\text { - Desconocimiento de la participación del partido en la capacidad para conducir la agenda } \\
\text { y decisiones políticas en el Congreso. } \\
\text { - Usurpación de la titularidad corporativa de la representación que posee solo parcialmen- } \\
\text { te -y no con plenitud de dominio- el representante. } \\
\text { - Favorecimiento y generalización de estrategias de corrupción para generar reagrupamientos } \\
\text { parlamentarios. }\end{array}$ \\
\hline $\begin{array}{l}\text { Quebrantamiento del } \\
\text { mandato ideologico } u \\
\text { organizacional del partido }\end{array}$ & $\begin{array}{l}\text { - Traición del afiliado o militante al ideario, organización o liderazgo del partido. } \\
\text { - Defraudación de la estrategia política, del uso de infraestructura organizativa y recursos } \\
\text { logísticos, y de la capacidad jurídica de agencia del partido. } \\
\text { - Disminución del índice de identificación con el sistema partidocéntrico en general y con } \\
\text { el partido del tránsfuga en particular. } \\
\text { - Afianzamiento de cultura disgregadora del vínculo político, desprestigio y debilitamien- } \\
\text { to de niveles de credibilidad en la oligarquía política. } \\
\text { - Confirmación de las tendencias a la despolitización de la vida social, y del concepto de } \\
\text { ciudadanía apolítica. } \\
\text { - Instalación del oportunismo y el pragmatismo político como método que define relaciones } \\
\text { inter e intrapartidarias - rasgo de subsistencia del patrimonialismo y clientelismo-. }\end{array}$ \\
\hline $\begin{array}{l}\text { Modificación unilateral de } \\
\text { los términos de elección y } \\
\text { nombramiento del } \\
\text { representante }\end{array}$ & $\begin{array}{l}\text { - Alteración de las relaciones de proporcionalidad y de pluralidad en el sistema de relacio- } \\
\text { nes entre mayorías y minorías. } \\
\text { - La dimisión frente al partido desconoce irreparablemente la facultad del partido de selec- } \\
\text { cionar a los miembros de su equipo parlamentario. } \\
\text { - Indefensión de los partidos para cancelar el apartamiento de miembros desleales que se } \\
\text { marginan de su asociación. } \\
\text { - Falseamiento inconsulto del ánimo electoral de la colectividad. } \\
\text { - Incentivo para generar y alcanzar expectativas individuales de los representantes median- } \\
\text { te el uso patrimonial o instrumental de los partidos para acceder a o retener un puesto de } \\
\text { representación política y obtener ganancia en la carrera política del tránsfuga. }\end{array}$ \\
\hline $\begin{array}{l}\text { Desviación del marco de } \\
\text { autonomía de la } \\
\text { autorización electoral }\end{array}$ & $\begin{array}{l}\text { - Anteposición del motivo o de la ventaja privada del tránsfuga sobre el vínculo funcional } \\
\text { de adscripción y compromiso con la asociación política. } \\
\text { - La motivación pragmática del tránsfuga — hipertrofia instrumental e individualista del } \\
\text { representante_- desconoce o deja sin efecto la base desde la que se autoriza al represen- } \\
\text { tante en el marco de las postulaciones legalmente presentadas. } \\
\text { - Desvirtúa los términos de intermediación y de agencia política a través de los partidos. } \\
\text { - Generación de marco de inestabilidad institucional por impredictibilidad e indefinición } \\
\text { de bloques políticos en el Parlamento. } \\
\text { - Concepción de partidos políticos como meras alianzas electorales de individuos inde- } \\
\text { pendientes para alcanzar escaños en el Congreso. } \\
\text { - Desnaturalización del Estado democrático de derecho por alteración discrecional de base } \\
\text { legal de representación. }\end{array}$ \\
\hline
\end{tabular}


Las manifestaciones del transfuguismo son las que suelen tomarse como lo que requiere modificación. Sin embargo, como puede verse el cuadro 2, el transfuguismo es un efecto del sistema político. Si bien por sí mismo genera manifestaciones de diversa naturaleza en el sistema político, como lo señalamos previamente, no es sino un sintoma que condensa y resulta de la cultura y de la ingeniería institucional expresada en el sistema de Estado, de representación y electoral. El síntoma es un fenómeno cuya irrupción llama la atención porque nos sitúa ante un acontecimiento irruptivo en la regularidad.

El síntoma es la expresión de una falta, de una mancha en las relaciones políticas. El transfuguismo, en tanto síntoma, indica una propiedad no ordinaria en el universo imaginario, simbólico o real en el que se encadena nuestra existencia. El transfuguismo llama la atención porque aparece como un episodio con capacidad para organizar un sistema de representación política que expresa a la vez que oculta, significa y rehúsa significación. El transfuguismo expresa una contradicción, un conflicto, entre lo que se estima normal y lo que cuestiona la normalidad como aparición insólita de la realidad en el universo simbólico. De ahí su poder de causar efectos y de mutar y adoptar formas diversas tras las cuales pulsa una realidad insimbolizable e insubordinable al plano discursivo, precisamente porque es lo que lo causa y genera su constitución fenoménica lo que permanecería inmodificable y, por lo tanto, que no desaparecería.

\subsection{El perfil del transfuguismo}

De modo que quede precisado el perfil del fenómeno bajo estudio, parece apropiado definir los elementos y presupuestos configuradores de la estructura del transfuguismo como fenómeno político-jurídico, ${ }^{17}$ el mismo que no es óbice, sin embargo, para que los partidos, en palabras de Alessandro Pizorno, sostengan en la sociedad la ilusión de elegir. ${ }^{18}$

Parte de dicho perfil asume como concepto de dicho fenómeno, según un sector de la doctrina, «[...] el deseo de mejorar expectativas de futuro sin intervención de auténticas motivaciones ideológicas», cuya naturaleza es la de un «[...] torpedo dirigido a la línea de flotación del sistema democrático», ${ }^{19}$ justificado

17 La estructura del hecho que se define como transfuguismo se toma de mi artículo «Transfuguismo y crisis postelectoral en el proceso de reinstitucionalización democrática», en la revista Derecho de la Facultad de Derecho de la Pontificia Universidad Católica, número 53, diciembre 2000, pp. 103-116.

18 Pizorno, Alessandro. «Intereses y partidos en el pluralismo». En Grompone, Romeo, Instituciones políticas y sociedad. Lecturas introductorias. Lima: IEP, 1995, p. 281.

19 De Esteban, Jorge. «El fenómeno español del transfuguismo político y la jurisprudencia constitucional». En Revista de Estudios Políticos (Nueva Época), número 70, octubre-diciembre, 1990, pp. 8-9. 
por «[...] el cambio de orientación ideológica de los partidos, la desaparición o crisis de partidos, el oportunismo o la búsqueda de mejores posiciones políticas, y la discrepancia con los ejecutivos de un partido", ${ }^{20} \mathrm{y}$ cuyos efectos consisten en el «[...] falseamiento de la representación política, el debilitamiento del sistema de partidos, el perjuicio en la gobernabilidad, el favorecimiento de la corrupción, y el deterioro de la cultura política democrática». ${ }^{21}$

\section{Cuadro 3.}

\section{Estructura típica del transfuguismo}

\begin{tabular}{|ll|}
\hline PRESUPUESTOS & \\
Sujeto activo & - Representante electo sin proclamar o proclamado. \\
Sujeto pasivo & - Representante incorporado al Congreso. \\
& - Partido político en cuya lista postuló. \\
Supuestos de hecho & - Abandono parlamentario en el que se registra membresía del tránsfuga. \\
& $\begin{array}{l}\text { - Alineamiento en otro grupo, o permanencia en la condición de independiente. } \\
\text { ELEMENTOS }\end{array}$ \\
Elementos objetivos & - Solicitud declarando la voluntad de desafiliación y sucesivo estatus del representante. \\
& $\begin{array}{l}\text { El plazo o la oportunidad de la desafiliación puede ocurrir antes de la procla- } \\
\text { mación o de la incorporación en el Congreso, o después de la incorporación } \\
\text { durante el período constitucional. }\end{array}$ \\
Elementos subjetivos & - Motivo o causa de la defección o adhesión a otro partido parlamentario.
\end{tabular}

Del cuadro 3 no es posible atribuir, a pesar de la percepción social y política contraria a su ocurrencia, connotaciones delictivas ni antijurídicas. No cabe, en efecto, asumir una misma política frente al fenómeno del transfuguismo, y ello no obstante la incidencia que su existencia representa en relación con el efecto que tiene respecto de la vigencia de normas constitucionales sustanciales, como la de que el poder se ejerce según el principio de la soberanía popular. No cabe,

20 Ibíd., pp. 11-12. En el caso específico de la crisis de partidos, o de su sistema, en el Perú, según se siga la posición de Cotler o Lynch, o la de Adrianzén y Tuesta, respectivamente, esta se expresa en los resultados obtenidos en las elecciones de 1993, de 1995, de 2000 y de 2001 por los partidos con representación parlamentaria hasta 1990. Los resultados electorales obtenidos son comparativamente tan limitados que difícilmente podrá negarse que el perfil de interacción entre partidos, Estado y sociedad es el mismo antes y después de 1992.

21 Ibíd., pp. 12-14. 
pues es posible advertir entre transfuguismos «inocuos» y transfuguismos políticamente «perjudiciales». ${ }^{22}$

En el plano jurídico positivo no existe un tipo legal que sancione la figura del transfuguismo, no obstante haberse dado la construcción constitucional — de origen europeo y que ha sido recogida de modo genérico por alguna opinión pública en el Perú- que ve en su ocurrencia un delito contra la forma de gobierno. ${ }^{23}$ Sí es cierto que existe la voluntad de desincentivar su ocurrencia mediante la limitación en el ejercicio de ciertos derechos, ${ }^{24}$ pero tales limitaciones no son sino la expresión del propósito de su indeseabilidad en un marco democrático que tendría como actor central de los procesos de intermediación el protagonismo de movimientos sociales que se expresan a través de los partidos políticos.

22 En mayo del 2005 se presentó el dictamen de la Comisión de Constitución y Reglamento en el Congreso de la República, en el cual se planteaba este tipo de clasificación, la que concebía al transfuguismo inocuo como legítimo en tanto que al transfuguismo pernicioso como ilegítimo. Ver el dictamen recaído en los proyectos de ley 8571/2003-CR, 8599/2003-CR, 8651/ 2003-CR, 8688/2003-CR, 8839/2003-CR, 9051/2003-CR, 12015/2003-CR y 12016/2003-CR, que proponen la reforma constitucional que incorpora la figura del transfuguismo, pp. 6-7. Sea cual fuese el caso, es necesario distinguir el móvil del transfuguismo que es lo que hace a fin de cuentas que se trate de una ocurrencia socialmente inocua o perniciosa. Será inocua cuando exista justificación para segregarse del partido con el que se llega al poder. Será perniciosa cuando se advierta en ella manifestaciones de lo que Oswaldo Medina Ilama el achoramiento, esto es, casos entre los que dicho autor consigna e incluye a los congresistas Alejandro Abanto Pongo y Manuel Lajo Lazo, en los que se advierte que un representante se vale de su mejor posición en el sistema jerárquico de representación pública para obtener ventajas privadas alcanzables solo a través del puesto de representante que ostenta.

23 Jorge de Esteban cita la propuesta de Jiménez de Parga, para quien el transfuguismo es concebido como un cáncer de nuestra democracia y el tránsfuga incurriría en actos previstos en el artículo 163 del Código Penal español. Esto es, se asimilarían dentro de la figura penal en la que el sujeto ejecuta actos directamente encaminados a cambiar ilegalmente la organización del Estado. Para salvar distancias, es importante no perder de vista que en el régimen español el sistema electoral es de lista cerrada, en tanto que en el Perú la opción por el doble voto preferencial define al nuestro como un sistema con lista abierta, lo cual es esencial y central para definir si el transfuguismo es una consecuencia legalmente permisible o, por el contrario, como ocurre en España, es más bien una forma de dejar sin efecto el sistema electoral de lista cerrada que busca justamente tanto evitar el acomodamiento del plantel de candidatos como la definición estable de los bloques partidarios.

24 Entre los que se cuenta, por ejemplo, el ejercicio efectivo de la libertad de asociación en general, o la sanción de pérdida del mandato de representación. Ver el dictamen de la Comisión de Constitución y Reglamento del Congreso peruano antes citado, el que propone la reforma del artículo 95 sobre pérdida del mandato parlamentario, 191 sobre pérdida de mandato de cargo regional, y 194 sobre pérdida de mandato de cargos municipales (ibíd., p. 15). Adicionalmente a las propuestas de inconstitucionalizar el transfuguismo, también se ha postulado su penalización, como en el caso del proyecto de ley 8688/2003-CR, presentado por el congresista Jorge del Castillo Gálvez, cuya finalidad era garantizar la fidelidad al voto ciudadano y sancionar penalmente el transfuguismo partidario, creando el artículo 359-A en el Código Penal, para los casos en los que el tránsfuga traicionara la voluntad popular «[...] con el objeto de percibir una suma de dinero u obtener una ventaja económica de cualquier índole, para sí o para un tercero», imponiendo en estos casos "pena privativa de la libertad no menor de cuatro ni mayor de seis años». En sentido similar se presentaron proyectos punitivos por las congresistas Vargas de Benavides (8839/2003-CR), Cabanillas (9051/2003CR), Ayaipoma Alvarado (12014/2004-CR) y Carrasco Távara (13366/2004-CR). 
Menos aún habría de esperar que ello ocurriera habida cuenta que el sistema electoral está diseñado para que el vínculo de la elección tenga relación mixta con el partido, además de la circunscripción en la que se presenta la candidatura, más allá de que el texto de la Constitución de 1993 introduce dos notas que neutralizan uno y otro vínculo cuando establece que los representantes no tienen mandato imperativo ni tienen por qué ceñirse a manual alguno de instrucción política, y asimismo que el sujeto imputado de representación no son ni los partidos ni las colectividades locales que eligen materialmente al representante sino la nación. Esta última es una entelequia abstracta a la que se imputan referencias de carácter eminentemente histórico-cultural respecto de cuya única lealtad tiene obligación constitucional, finalmente, el representante, además, por supuesto, de su propia conciencia.

\subsection{Ilusión de elegir y anomia sistémica}

Teóricos de la elección racional han realizado una contribución muy importante al postular las pautas para que del proceso de agregación de preferencias individuales pueda predicarse que se trata de un proceso colectivo efectivamente democrático. ${ }^{25}$ Uno de los principales aportes es el que realiza Kenneth Arrow, cuando define en su teorema las condiciones para que una decisión colectiva sea efectivamente democrática. La ilusión que nos dan los procesos electorales es que la mecánica nos asegura una decisión colectiva inmunizada de autoritarismo. Sin embargo, el hecho es que el propio proceso electoral oculta altos niveles de arbitrariedad no menos que de irracionalidad que permite llegar a la conclusión de que los mecanismos electorales no expresan en realidad un producto colectivo sino de una manera forzada.

El mito de la elección política como hito que redime la anomia y asegura un sistema de representación parece no ser poco más que una imputación con insuficiente sustento material. Las ineficiencias de los sistemas y mecanismos electorales no permiten a lo mucho sino contar con un resultado, pero no su calidad racional ni su condición democrática. Y si es así que las decisiones colectivas que se derivan de los procesos electorales no son ni racionales ni democráticas, mal cabe sustentar que exista en efecto un supuesto dogma de la soberanía popular ni de la voluntad democrática de una comunidad.

Tratándose de procesos como son los procesos políticos, que son por definición y en esencia contingentes, más allá de la ilusión de vivir en una sociedad

25 Por ejemplo, Kenneth Arrow (Social choice and individual values, Yale University Press, 1963); Anthony Downs (An economic theory of democracy, Harper and Row, 1956); William RIKER (Liberalism against populism. A confrontation between the theory of democracy and the theory of social choice, Waveland Press, 1988); y Kenneth SHEPSLE y Mark BONCHECK (Analyzing politics. Rationality, behavior and institutions, W. W. Norton \& Company, 1997). 
democrática no tendría sustento tampoco la afirmación de que el transfuguismo sea un síntoma de anomia política. Por el contrario, mayor sentido parece tener que la imposibilidad de contar con decisiones colectivas democráticas desnuda la condición política de la sociedad revelando que es poco lo que puede resultar de procesos de agregación de preferencias individuales más allá de resultados arbitrarios. En suma, la redención de la anomia a través de mecanismos de agregación de preferencias no es auspiciosa y, por el contrario, debe llevarnos a una conclusión poco optimista: si los procesos colectivos no permiten superar la anomia original, todo resultado obtenido luego de la aplicación de la mecánica de agregación de preferencias no deja de ser un resultado arbitrario y las decisiones colectivas no pueden abandonar su carácter falaz.

Ante la constatación de que las decisiones colectivas difícilmente pueden dejar de ser decisiones arbitrarias, el sustento para cuestionar el transfuguismo se debilita. La sacralidad de los procesos electorales queda desmitificada. No hay ofensa contra el vínculo de representación. La agencia de los operadores del sistema de representación que son los partidos políticos deja su carácter de intocable. El sistema político, por lo tanto, se mueve en una espiral de presunciones ocultas que se respaldan en una creencia colectiva indemostrada. Tenemos una enorme disponibilidad para creer en una realidad que resulta de un proceso de condicionamiento cultural sin control alguno. Realidad que, además, recibe el poderoso y perverso impacto de la construcción de las opiniones públicas a través de la imagen y los medios de comunicación masiva que se aseguran de darle solidez colectiva a un cuerpo sistemático de creencias poco más que fantásticas. ¿Qué es la realidad democrática más allá de lo que hace de ella un conjunto de creencias compartidas por una época, y más allá del sustento que tengan dichas creencias para sostenerse por sí mismas?

\section{A modo de conclusión}

Visto el contexto histórico en el que se desarrolla y prolifera, el transfuguismo es una experiencia insuficientemente indetenible e irredimible con el instrumental normativo. No hay ley con el poder de detener una realidad emergente y desbordante.

El transfuguismo como tal solo es posible no porque haya congresistas o políticos tránsfugas, sino porque existe, antes, una relación y condiciones materiales favorables al transfuguismo entre los congresistas y políticos tránsfugas y los grupos políticos de los que se apartan y a los que migran. El marco que constituye la relación tránsfuga no es solo la intención y propósito de serlo, sino la filiación a un grupo del que se sale y la propuesta para migrar a otro.

El tipo de sistema de partidos, en buena cuenta, y el tipo de cada uno de los partidos en los que se inscriben quienes actuarán el transfuguismo, la estructura 
que funda, permite, avala, replica y reproduce el transfuguismo. Únicamente si se modificara el tipo de partidos y, por lo tanto, variara el tipo de sistema de partidos en el que florece el transfuguismo, cabría que este disminuyera o se extinguiera. Mientras esa condición no se dé, permanecen los incentivos para la perennización de este fenómeno, que es, en último término, un fenómeno afín a la naturaleza de las agrupaciones humanas existentes en el actual momento histórico.

Visto que no cabe esperar un retroceso respecto de la experiencia del transfuguismo en la vida política nacional, no sin el cambio de la lógica organizacional en la vida de los partidos políticos en el ámbito nacional, el balón pasa al espacio de los propios partidos, quienes tienen el reto de ordenar los destinos de la república según perspectivas de largo aliento y a largo plazo, antes que según los intereses inmediatos de ocupar y posicionarse del poder. Sin embargo, ellos mismos no escapan de la tendencia y cultura hegemónica, más próxima al utilitarismo y la maximización inmediata de los intereses del individuo que a la valoración de la comunidad como espacio en el que cada sujeto y cada cuerpo cumple una función necesaria para el óptimo desarrollo del órgano republicano del que todos los ciudadanos formamos parte en nuestra república. En este contexto, por lo tanto, parece que el reto consiste en el rescate de los valores de la comunidad y en corregir la posición desbordante del individualismo en la cultura de complacencia y de consumismo que se fomenta en la esfera pública, tanto por los propios agentes del mercado como por el marketing en el que tienen participación activa los medios de comunicación.

Este es, pues, un caso en el que el mercado debe ser intervenido y corregido, pero intervenido y corregido no por el Estado, sino a partir única y exclusivamente de la mejor conciencia de cada uno de los ciudadanos y de los líderes que se rebelen contra la dinámica del automatismo de las no tan ocultas «manos invisibles» que orientan las preferencias de las personas. Contra la falta de conciencia, poco se puede hacer. En consecuencia, debiera concluirse que no hay modo de salir del entrampamiento a menos que se esté dispuesto a los aislamientos inherentes a la oposición y rebeldía que deben mantenerse en contra del sistema imperante.

Porque la vida y acción política no pueden desarrollarse sin el deseo de poder de quienes en ella operan las instituciones, es imposible negar que el goce de tener poder es un incentivo poderoso en la carrera y la actividad política. Quien afirmara que hace vida política por puro desprendimiento, no termina de decir la verdad. Pero quien subordine su relación con el grupo político al que pertenece o su relación con las colectividades a las que representa de manera que grupo y colectividad sean sometidos a su puro goce por el poder, tergiversa e invierte el sentido republicano de la institución representativa en una comunidad democrática. La pura voluntad e interés de los actores 
en el proceso político, sea parlamentario o no, como motivo de acción y de adopción de conductas, constituye una perversión de la cultura y de las instituciones.

Existen situaciones y casos en los que el transfuguismo se justifica y hasta resulta moralmente recomendable. No es una modalidad en sí misma condenable. Es en todo caso la disposición de armonizar juiciosa, reflexiva, crítica, argumentada y razonablemente la libidinalidad elemental del poder con el uso de este para el servicio a la república el mejor árbitro sobre la decisión y la conducta adoptada. Estructurar ordenadamente la vida de cada representante supone reconocer el propio deseo y goce del poder, no menos que la orientación prudente y virtuosa del apetito a satisfacer para beneficiar a la comunidad.

No cualquier deseo de poder es aceptable, como no cualquier medio para beneficiar a la comunidad es bueno. El punto de quiebre se encuentra en la orientación prudente y virtuosa de la conducta y juicio del representante para equilibrar su deseo e impulso individual con el servicio político, que es el servicio al bienestar, a los intereses y a la voluntad de la república. 